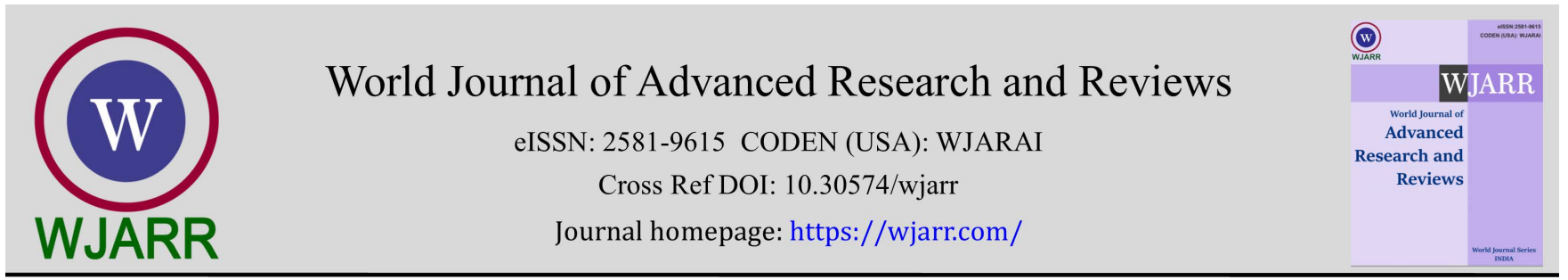

(RESEARCH ARTiClE)

Check for updates

\title{
Emulsion formulation assays based on natural substances stimulating the hair growth and evaluation of its biological activity
}

Emery Kalonda Mutombo 1, ${ }^{*}$, Marsi Mbayo Kitambala 1, Victor Ngambi Nyambi ${ }^{2}$, Joseph Mbayo Mukala ${ }^{3}$, Evodie Numbi Wa Ilunga ${ }^{2}$, Jean-Baptiste Kalonji Ndumba ${ }^{2}$, Kahumba Byanga Joseph ${ }^{2}$ and Jean-Baptiste Lumbu Simbi ${ }^{1}$

${ }^{1}$ Department of Chemistry, Faculty of Sciences, University of Lubumbashi, Lubumbashi, DR Congo.
${ }^{2}$ Faculty of Pharmaceutical Sciences, University of Lubumbashi, Lubumbashi, DR Congo.
${ }^{3}$ Department of Public Health, Faculty of Medicine, University of Kalemie, Kalemie, DR Congo.

World Journal of Advanced Research and Reviews, 2021, 10(03), 012-024

Publication history: Received on 20 March 2021; revised on 24 May 2021; accepted on 26 May 2021

Article DOI: https://doi.org/10.30574/wjarr.2021.10.3.0119

\begin{abstract}
Aim: This study aims to identify the physicochemical parameters for the stability of emulsions prepared with medicinal plant extracts (i); to study the optimum parameters contributing to the stabilization of emulsions used for hair care (ii); to determine the physicochemical and galenical conditions for better stable formulation and the reproducible to ensure a pharmaceutical use (iii) and finally to evaluate the capillary activity of the emulsions prepared in vivo on Cavia porcellus L. (iv).

Methodology: To achieve the goal of this study, the water-oil emulsions prepared by the mixture of Hibiscus rosa-sinensis L. flowers extracts (1mg/g and 10mg/g), Cannabis sativa L. seeds oil (1 mg/g and 10mg/g), Ricinus communis L. oil, Olea europaea crude oil, and beeswax. The prepared emulsions were tested in vivo on Cavia porcellus L. for 28 days following the protocols established in preliminary studies on cosmetic systems with natural extracts as well as those established for the evaluation of the antialopecic activity.

Results: The water-oil emulsion, with a ratio of 4/6, a Hydrophilic/Lipophilic Balance [HLB] of 7, an average globule size of $2.57 \pm 1,91 \mu \mathrm{m}$ made with Cannabis sativa L. seed oil (10mg/g), Ricinus communis L. oil, Olea europaea oil, extract of flowers of Hibiscus rosa-sinensis L. (10mg/g), and beeswax exhibited good stability as well as stimulating activity of capillary growth.

Conclusion: The stability of a water-in-oil emulsion formulated with natural substances selected for this research depends on the hydrophilic/lipophilic balance, uniformity of the globules distribution in their average size as well as the hydrophilic/lipophilic ratio.
\end{abstract}

Keywords: Water-oil Emulsion; Hair diseases; Medicinal plant and Antialopecic activity

\section{Introduction}

Hair performs various functions including protection and temperature control of the head and sensory receptors to which special attention should be given to restore any disturbance. However, they are affected by pathologies that destroy all their functions among which can be performed on ringworm and alopecia [1, 2, 3, 4].

In Africa in general and in the DRC in particular, effective products for hair treatment are rare and expensive. People, with these diseases, resort to traditional formulations prepare with local raw materials. These products effect genetic, hormonal, and infectious pathologies implicated in hair loss and other diseases of the scalp $[5,6]$.

\footnotetext{
${ }^{*}$ Corresponding author: Kalonda Mutombo Emery

Department of Chemistry, Faculty of Sciences, University of Lubumbashi, DR Congo.

Copyright $(2021$ Author(s) retain the copyright of this article. This article is published under the terms of the Creative Commons Attribution Liscense 4.0.
} 
Studies on traditional remedies in the treatment of several diseases have shown that the results of pharmacological tests are consistent in $75 \%$ of cases with the traditional use of plants [7]. They showed that active ingredient extracts from medicinal plants, especially vegetable oils, have a positive effect on hair growth. This is the case of the activity of Cocos nucifera oil that prevents hair loss [6, 8], Ricinus communis oil entering into the composition of medicinal preparations [9] and cosmetic preparations [6] as well as Cannabis sativa L. seed oil [10] which stimulate hair growth $[5,6]$. In India, the flowers of Hibiscus rosa-sinensis are traditionally used to promote growth, prevent hair loss and premature graying, and fight dandruff $[4,8]$.

In this work, we sought to incorporate plant extracts in an emulsifying formulation of water-oil type (W/0) for fighting against hair loss.

The objective of this study is:

- To identify the physicochemical parameters for the stability of emulsions prepared with medicinal plant extracts;

- To study the optimum parameters contributing to the stabilization of emulsions used for hair care;

- To determine the physicochemical and galenical conditions for better stable formulation and reproducible to ensure pharmaceutical use and finally;

- To evaluate the capillary activity of the emulsions prepared.

To achieve these goals, water-oil emulsions comprising the mixture of Hibiscus rosa-sinensis L. flower extracts, Cannabis sativa L. seeds oil, Ricinus communis L. oil, Olea europaea crude oil, and beeswax were prepared. The prepared emulsions were tested in vivo on Cavia porcellus L. following the protocols established in preliminary studies on cosmetic systems with natural extracts as well as those established for the evaluation of the antialopecic activity.

\section{Material and methods}

\subsection{Material used}

The raw material was selected according to its availability in our environment and it allowed us to prepare an emulsion capable of improving hair growth. These are seeds of Cannabis sativa L., flowers of Hibiscus rosa-sinensis L., seeds of Ricinus communis L., oil of Olea europaea and beeswax, glycerol, distilled water, and Tween 80 as active surfactant. For the evaluation of the activity on capillary stimulation in vivo, Cavia porcellus L., the small rodent of the family Cavidae was used.

\subsection{Harvesting and conditioning of the raw material}

Different seeds used for obtaining oils (Cannabis sativa seeds and Ricinus communis) were harvested at $41 \mathrm{~km}$ from the city of Lubumbashi on the Kasenga road in 2012; the Olea europaea oil produced by the Colruyt group from South Africa has been purchased on the local market. Hibiscus flowers were harvested in Lubumbashi. The beeswax was collected in the surroundings of Kolwezi (in the forest) at $300 \mathrm{~km}$ from Lubumbashi in 2012.

After harvesting plant material (flowers and seeds) and their drying in the open air in the laboratory of the Department of Chemistry of the Sciences Faculty of the University of Lubumbashi, they were pulverized in a mill Winsor brand. The beeswax was cleared of residual honey by centrifugation. Cannabis seeds were cleaned with water, dried, and pulverized before extraction [11].

\subsection{Extraction of crude substances}

Ricinus communis seed oil was obtained by cold expression using a hand press and purified by decantation followed by filtration. The Cannabis sativa oil was obtained by pulverizing the seeds and then macerating the seeds in petroleum ether for 24 hours. After filtration, the solvent was removed under vacuum on a rotary evaporator brand Bibby RE200. The beeswax was obtained by the extraction process by melting in hot water at $80^{\circ} \mathrm{C}$ and its purification $[12,13]$.

The crude extract of Hibiscus rosa-sinensis flowers was obtained by maceration of the dried and pulverized flowers in a methanol-water mixture $(80 \div 20)$ for 48 hours. After filtration, the extract obtained, dried under vacuum in a rotary evaporator, and was then dissolved in Aqua conservans at $100 \mathrm{mg} / \mathrm{ml}[12,13]$.

\subsection{Preparation of the emulsion}

The individual components (Cannabis sativa L. seed oil, Hibiscus rosa-sinensis L. flower extract, Ricinus Communis L. seed oil, Olea europaea oil and beeswax, glycerol, and distilled water) weighed on the Mettler Toledo analytical balance were each dissolved in the aqueous and/or oil phase and Tween 80 was used as surfactant. Both phases were heated to $70^{\circ} \mathrm{C}$ 
in a GMBH brand sand bath until the wax was completely melted. The inner phase (continuous phase) into the outer phase (dispersed phase) was added gradually and stirred vigorously by Geepas brand rotary electric mixer. The mixture was cooled to room temperature while stirring slowly $[14,15]$.

The three emulsions (E) prepared had a thick cream appearance and a touch of cold cream:

- E1: Emulsified Base

- E2: Emulsified Base + Hibiscus flowers methanolic extract (1mg/g), Cannabis oil (1mg/g)

- E3: Emulsified Base + Hibiscus flowers methanolic extract (10mg/g), Cannabis oil (10mg/g)

\subsection{Determination of physicochemical parameters of emulsions prepared}

\subsubsection{Determination of the required $H L B$}

Three $100 \mathrm{~g}$ emulsions with Hydrophilic Lipophilic Balance (HLB) of 5, 6, and 7 were prepared to determine the required HLB [16]. Then we studied the parameters below to evaluate the stability at different HLB: the determination of the size distribution of the globules and the determination of emulsion stability at different temperatures.

Determination of the size distribution of the globules

Dissolve $2 \mathrm{~g}$ of emulsion in $10 \mathrm{~g}$ of oil. After a slight agitation, the dilution was left to rest for $15 \mathrm{~min}$. A drop of this mixture was then placed on a slide, covered with a coverslip and observed under the Olympus CKX 41 microscope. The size of 300 globules was then classified into five different size classes [16].

Determination of emulsion stability at different temperatures

$10 \mathrm{ml}$ of each emulsion are left to stand in test tubes for 24 hours: the first at $4^{\circ} \mathrm{C}$ in a Samsung fridge, the second at $40^{\circ} \mathrm{C}$ in a Memmert oven, and the third at room temperature $\left(25^{\circ} \mathrm{C}\right)$. After this time, the degree of creaming or sedimentation was calculated as the ratio of the height of the skimmed or sedimented part to that of the emulsion in the test tube [16].

\subsubsection{Determination of the hydrophilic/lipophilic ratio}

Two required HLB of emulsions were prepared with hydrophilic/lipophilic ratios (4/6 and 3/7) and their stability was then studied $[14,15]$.

\subsubsection{Determination of $\mathrm{pH}$}

The $\mathrm{pH}$ of the emulsions having the required HLB prepared with extracts was measured using the pH-meter brand PHMT600 KOMET. After, the pH was adjusted with acetic acid to achieve pH 5.5 (Tableau 1) [16].

Table $1 \mathrm{pH}$ adjustment of emulsions

\begin{tabular}{|c|c|c|}
\hline Emulsion & $\mathbf{p H}$ after preparation & $\mathbf{p H}$ after adjustment \\
\hline E1 & 6.6 & 5.5 \\
\hline E2 & 6.6 & 5.5 \\
\hline E3 & 6.3 & 5.5 \\
\hline
\end{tabular}

\subsubsection{Determination of the emulsion behavior}

The sense of the emulsion was examined by the dilution method in a test tube by taking two samples of $1 \mathrm{~g}$ each, diluted respectively in $5 \mathrm{ml}$ of olive oil and $5 \mathrm{ml}$ of distilled water. After homogenization, the behavior was observed one hour later without moving the tube $[14,15,17]$.

\subsection{Biological activity assessment}

In-vivo tests were performed on 12 guinea pigs (Cavia porcellus L.) (See table 2) of more than 2 months old (8 males and 4 females) whose the weight ranged from 350 to $450 \mathrm{~g}$. After acclimatization at the Faculty of Pharmaceutical Sciences of the University of Lubumbashi for 7 days, all guinea pigs were shaved on a $4 \mathrm{~cm} \times 7 \mathrm{~cm}$ surface on their dorsal side with an electric clipper Wall brand according to the method used by Park et al. (2011) [18]. They were then randomized into three groups and each group received the topical application on the area-shaved one of the following treatments: Emulsified base without plant extracts (Group II), emulsified base containing $1 \mathrm{mg} / \mathrm{g}$ of plant extracts (Group III), and 
emulsified base containing $10 \mathrm{mg} / \mathrm{g}$ of plant extracts (Group IV). Another group, used as a reference, was plucked following the same pattern, but it had not received the treatment (Group I).

Table 2 In vivo test procedure

\begin{tabular}{|c|c|c|l|l|l|}
\hline Group & $\begin{array}{c}\text { Number of } \\
\text { guinea pigs }\end{array}$ & Group & Composition of treatment received & Dose & Time \\
\hline E0 & 3 & I & No treatment & - & - \\
\hline E1 & 3 & II & $\begin{array}{l}\text { Emulsified Base: Castor oil, olive oil, beeswax, } \\
\text { water }\end{array}$ & 1 per day & $5: 00$ PM \\
\hline E2 & 3 & III & $\begin{array}{l}\text { Emulsified Base }: \text { Hibiscus flowers methanolic } \\
\text { extract (1mg/g), Cannabis oil (1mg/g) }\end{array}$ & 1 per day & $5: 00$ PM \\
\hline E3 & 3 & IV & $\begin{array}{l}\text { Emulsified Base }: \text { Hibiscus flowers methanolic } \\
\text { extract (10mg/g), Cannabis oil (10mg/g) }\end{array}$ & 1 per day & $5: 00$ PM \\
\hline
\end{tabular}

The treatment was administered for 21 days between 5 and $6 \mathrm{pm}$. The hair growth was monitored by simple observation and by photography using a Samsung digital camera of the waxed dorsal part of the guinea pigs $\left(1^{\text {st }}, 3^{\text {rd }}, 14^{\text {th }}, 21^{\text {th }}\right.$, and $28^{\text {th }}$ days) to follow the evolution of hair growth over time until total coverage of the starting coat [18].

\section{Results}

\subsection{Results of extraction}

The extraction of substance was done by the cold expression for Ricinus communis seed oil, the maceration in petroleum ether for the Cannabis sativa seed oil. The extraction process obtained the beeswax by melting in hot water, and the Hibiscus rosa-sinensis flowers extract by maceration in the mixture of methanol and water. The results obtained are grouped in the following table 3.

Table 3 Extraction of substances

\begin{tabular}{|l|l|c|c|c|}
\hline Material ID & Part Used & $\begin{array}{c}\text { Weight before } \\
\text { extraction (g) }\end{array}$ & Extract (g) & $\begin{array}{c}\text { Extraction } \\
\text { Efficiency (\%) }\end{array}$ \\
\hline Cannabis sativa & Seeds & 1000 & 150 & 15 \\
\hline Hibiscus rosa-sinensis & Flowers & 1000 & 440 & 44 \\
\hline Ricinus communis & Seeds & 1000 & 245 & 24.5 \\
\hline Bee alveoli & Beeswax cell & 1000 & 553 & 55.3 \\
\hline
\end{tabular}

That the extraction (Table 3) was carried out with a yield of 44\% for Hibiscus rosa-sinensis flowers extract, $24.5 \%$ for Ricinus communis seeds oil, and $15 \%$ for Cannabis sativa seeds oil. Moreover, the beeswax was extracted from bees' cells with a yield of $55.3 \%$.

\subsection{Determination of HLB required}

The required HLB was determined by the stability of emulsions at various temperatures after 24 hours. The results obtained are shown in Table 4 and Figure 1.

All emulsions showed good stability at room temperature. On the other hand, at high temperature $\left(4^{\circ} \mathrm{C}\right)$, the $\mathrm{HLB} 7$ emulsion showed the highest stability $(97.1 \%)$ and it showed better stability at $40^{\circ} \mathrm{C}(95.1 \%)$. On the other hand, the HLB 5 emulsion was the least stable to temperature variation, i.e. $93.4 \%$ at $4^{\circ} \mathrm{C}$ and $92.5 \%$ at $40^{\circ} \mathrm{C}$. Finally, the $\mathrm{HLB} 6$ emulsion at $4^{\circ} \mathrm{C}(95.50 \%)$ showed almost the same stability as the HLB 7 emulsion at $40^{\circ} \mathrm{C}(95.1 \%)$. 
Table 4 HLB required determination

\begin{tabular}{|c|c|c|c|c|}
\hline HLB & $\mathrm{T}\left({ }^{\circ} \mathrm{C}\right)$ & Lipid layer (\%) & Emulsified layer (\%) & Aqueous layer (\%) \\
\hline \multirow{4}{*}{5} & 4 & 0.00 & 93.40 & 6.60 \\
\cline { 2 - 5 } & 22 & 0.00 & 100.00 & 0.00 \\
\cline { 2 - 5 } & 40 & 7.50 & 92.50 & 0.00 \\
\hline \multirow{3}{*}{6} & 4 & 0.00 & 95.50 & 4.50 \\
\cline { 2 - 5 } & 22 & 0.00 & 100.00 & 0.00 \\
\cline { 2 - 5 } & 40 & 0.90 & 94.30 & 4.80 \\
\hline \multirow{3}{*}{7} & 4 & 0.00 & 97.10 & 2.90 \\
\cline { 2 - 5 } & 22 & 0.00 & 100.00 & 0.00 \\
\cline { 2 - 5 } & 40 & 4.90 & 95.10 & 0.00 \\
\hline
\end{tabular}

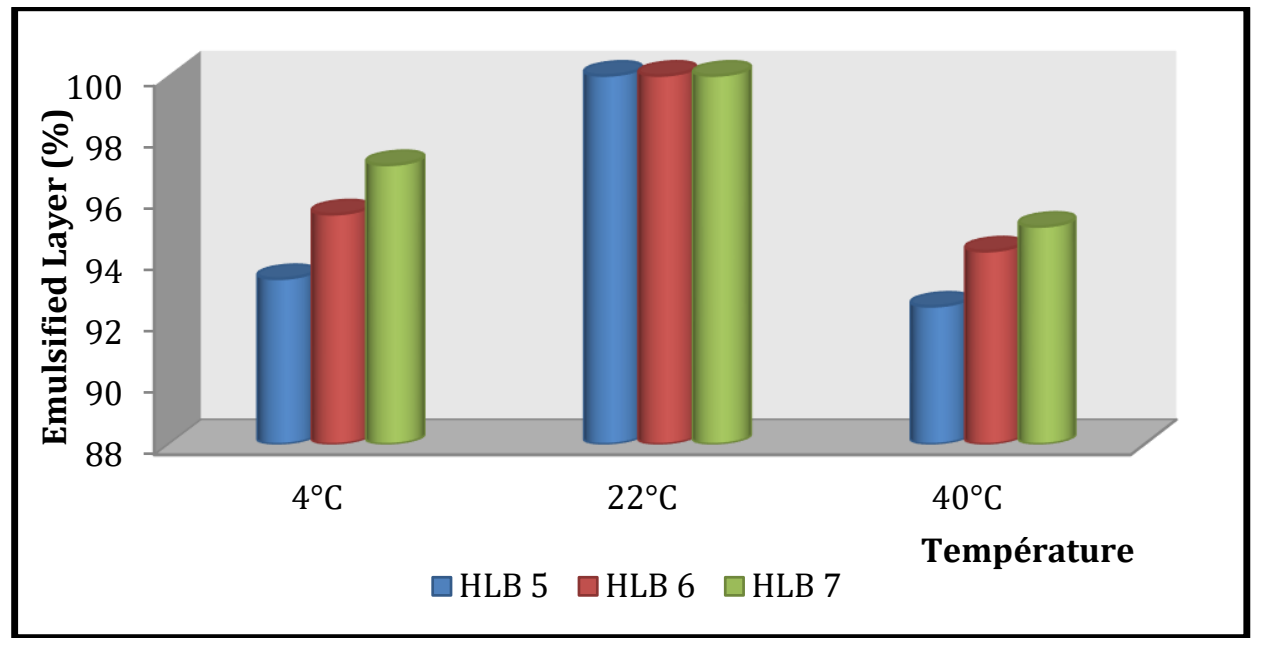

Figure 1 Emulsion stability at different temperatures after 24 hours

\subsection{Size distribution of the globules}

The microscopic observation allowed evaluating the size distribution of the globules in the emulsions, which helped to group the globules according to their size (Table 5 and Figure 2).

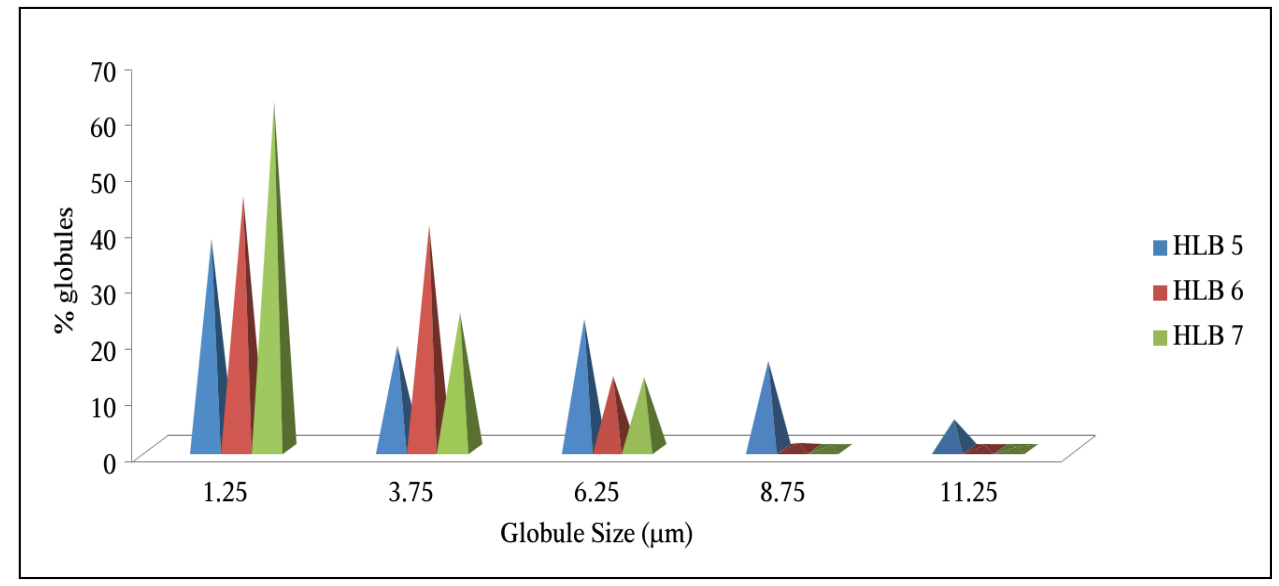

Figure 2 Globules Size Distribution 
Table 5 Results of determination of the globules size distribution

\begin{tabular}{|c|c|c|c|c|c|c|}
\hline $\begin{array}{l}\text { Type of } \\
\text { HLB }\end{array}$ & Class & $\begin{array}{c}\text { Size } \\
(\mu \mathrm{m})\end{array}$ & Number & $\begin{array}{c}\text { Percentage } \\
{[\%]}\end{array}$ & $\begin{array}{c}\% \\
\text { Cumulated } \\
\end{array}$ & $\begin{array}{c}\text { Average } \\
\text { Size } \\
\end{array}$ \\
\hline \multirow{6}{*}{ HLB 5} & {$[0.0-2.5]$} & 1.25 & 113 & 37.67 & 37.67 & \multirow{6}{*}{$4.57 \pm 3.17 \mu \mathrm{m}$} \\
\hline & {$[2.5-5.0]$} & 3.75 & 55 & 18.33 & 56.00 & \\
\hline & {$[5.0-7.5]$} & 6.25 & 69 & 23.00 & 79.00 & \\
\hline & {$[7.5-10.0]$} & 8.75 & 47 & 15.67 & 94.67 & \\
\hline & {$[10.0-12.5]$} & 11.25 & 16 & 5.33 & 100.00 & \\
\hline & Total & & 300 & 100 & & \\
\hline \multirow{6}{*}{ HLB 6} & {$[0.0-2.5]$} & 1.25 & 136 & 45.33 & 45.33 & \multirow{6}{*}{$2.97 \pm 1.94 \mu \mathrm{m}$} \\
\hline & {$[2.5-5.0]$} & 3.75 & 120 & 40.00 & 85.33 & \\
\hline & {$[5.0-7.5]$} & 6.25 & 39 & 13.00 & 98.33 & \\
\hline & {$[7.5-10.0]$} & 8.75 & 3 & 1.00 & 99.33 & \\
\hline & {$[10.0-12.5]$} & 11.25 & 2 & 0.67 & 100 & \\
\hline & Total & & 300 & 100 & & \\
\hline \multirow{6}{*}{ HLB 7} & {$[0.0-2.5]$} & 1.25 & 186 & 62.00 & 62.00 & \multirow{6}{*}{$2.57 \pm 3.91 \mu \mathrm{m}$} \\
\hline & [2.5-5.0] & 3.75 & 73 & 24.33 & 86.33 & \\
\hline & {$[5.0-7.5]$} & 6.25 & 38 & 12.67 & 99.00 & \\
\hline & {$[7.5-10.0]$} & 8.75 & 2 & 0.67 & 99.67 & \\
\hline & {$[10.0-12.5]$} & 11.25 & 1 & 0.33 & 100.00 & \\
\hline & Total & & 300 & 100 & & \\
\hline
\end{tabular}

The average size of HLB5 globules was $4.57 \pm 3.17 \mu \mathrm{m}$ with an almost uniform distribution of 3.75-8.75 $\mu \mathrm{m}$ fractions. HLB6 globules had an average size of $2.97 \pm 1.94 \mu \mathrm{m}$ with a larger fraction between $1.25 \mu \mathrm{m}(45 \%)$ and $3.75 \mu \mathrm{m}(40 \%)$. Finally, the average size of HLB7 was $2.57 \pm 3.91 \mu \mathrm{m}$ with a high concentration of $1.25 \mu \mathrm{m}$ globules (186 globules out of 300 , i.e. $62 \%$ ).

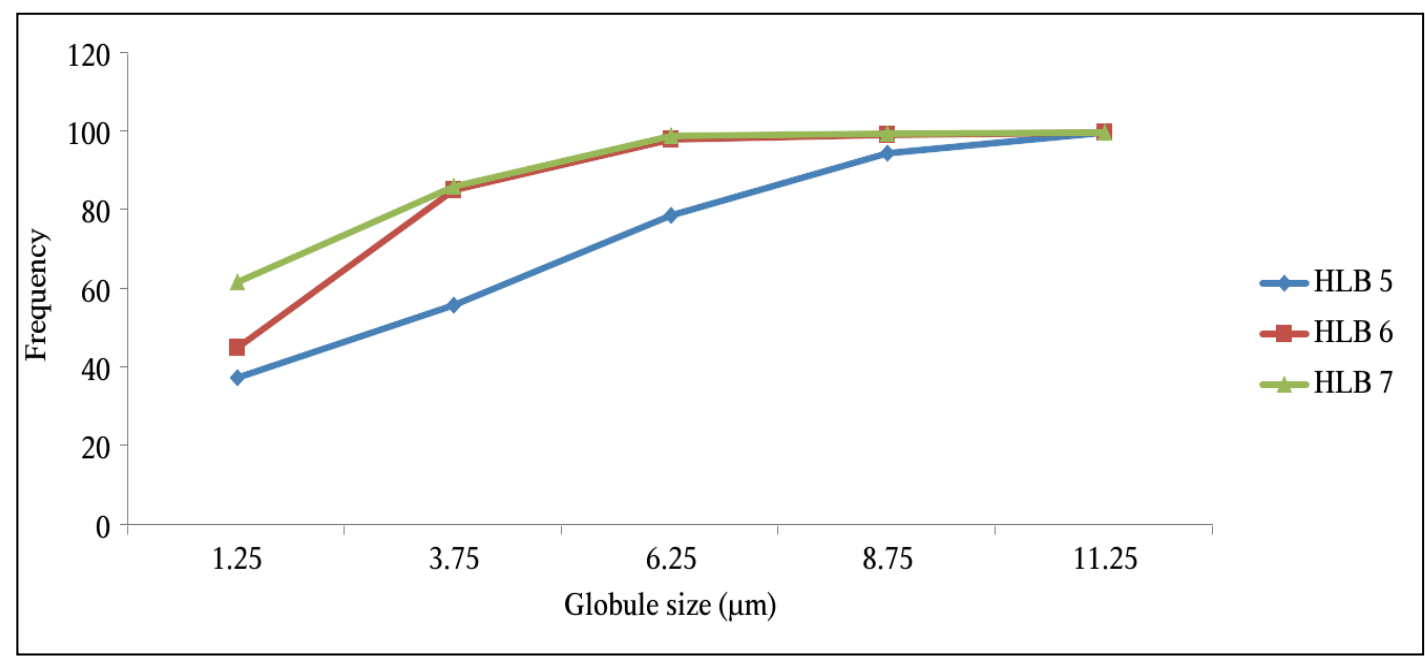

Figure 3 Cumulative frequency of globule sizes

The cumulative frequency curve (Figure 3) of the globules of the HLB 5 emulsion shows that $56 \%$ of the globules have a size less than or equal to $3.75 \mu \mathrm{m}$. On the other hand, those of the HLB 6 emulsion showed that $85.33 \%$ of the globules are less than or equal to $3.75 \mu \mathrm{m}$ in size, and those of the HLB 7 emulsion show that $86.33 \%$ of the globules are less than or equal to $3.75 \mu \mathrm{m}$ in size. 


\subsection{Determination of hydrophilic/lipophilic ratio}

According to the HLB 7 emulsion texture, the distribution of the globules' size as a function of the Hydrophilic/Lipophilic ratio was determined at different temperatures. The results of this investigation are shown in Table 6 below.

Table 6 Results of globule size distribution in HLB7 3/7 and 4/6

\begin{tabular}{|c|c|c|c|c|c|c|}
\hline Type of HLB & Class & Size $(\mu \mathrm{m})$ & Number & Percentage & $\%$ Cumulated & Average Size \\
\hline \multirow{6}{*}{ HLB $73 / 7$} & {$[0.0-2.5]$} & 1.25 & 127 & 42.33 & 42.33 & \multirow{6}{*}{$3.51 \pm 2.32 \mu \mathrm{m}$} \\
\hline & {$[2.5-5.0]$} & 3.75 & 91 & 30.33 & 72.66 & \\
\hline & [5.0-7.5] & 6.25 & 66 & 22.00 & 94.66 & \\
\hline & [7.5-10.0] & 8.75 & 15 & 5.00 & 99.66 & \\
\hline & {$[10.0-12.5]$} & 11.25 & 1 & 0.33 & 100.00 & \\
\hline & Total & & 300 & 100.00 & & \\
\hline \multirow{6}{*}{ HLB 7 4/6 } & [0.0-2.5] & 1.25 & 186 & 62 & 62,00 & \multirow{6}{*}{$2.57 \pm 1.91 \mu \mathrm{m}$} \\
\hline & [2.5-5.0] & 3.75 & 73 & 24.33 & 86.33 & \\
\hline & [5.0-7.5] & 6.25 & 38 & 12.67 & 99,00 & \\
\hline & [7.5-10.0] & 8.75 & 2 & 0.67 & 99.67 & \\
\hline & [10.0-12.5] & 11.25 & 1 & 0.33 & 100,00 & \\
\hline & Total & & 300 & 100,00 & & \\
\hline
\end{tabular}

Figure 4 (Stability of emulsion as a function of temperature) and figure 5 (Distribution of globules as a function of size) showed the evolution of the stability of emulsions formulated from HLB7.

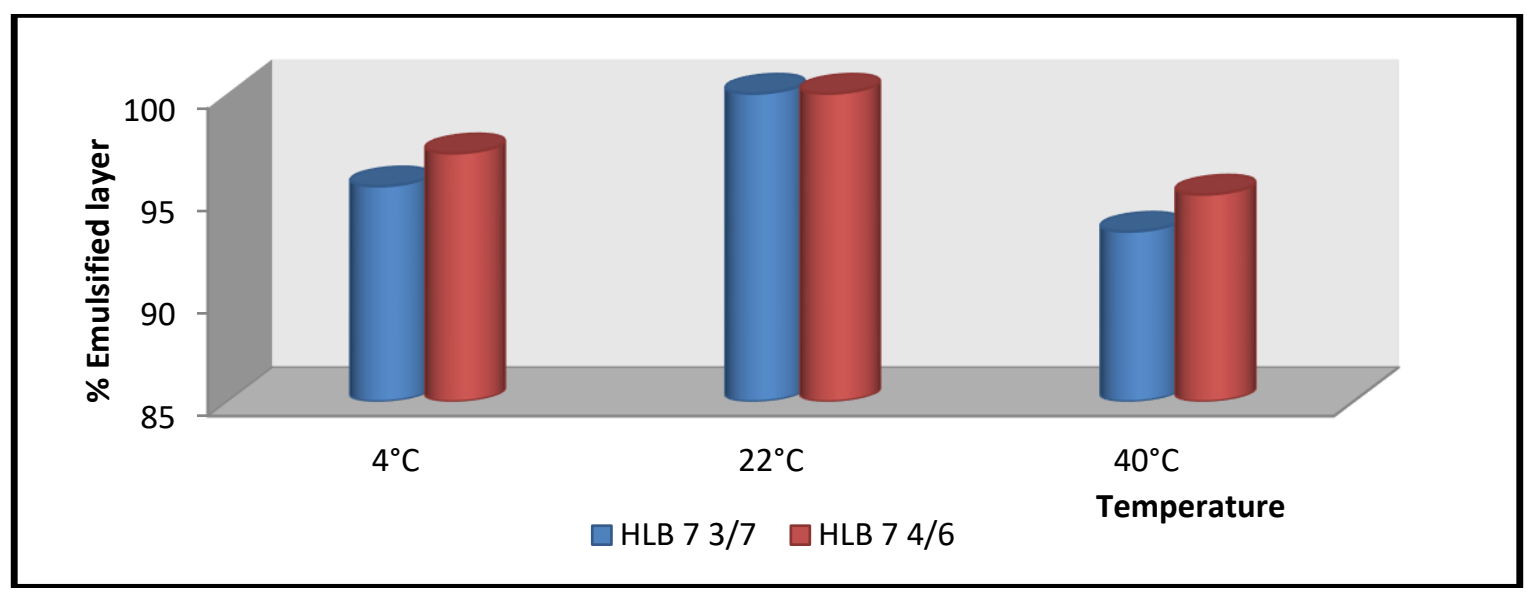

Figure 4 Stability of HLB7 emulsion at different temperatures after 24 hours

The study of the stability of HLB 7 emulsions at different temperatures with different hydrophilic/lipophilic ratios (Table 6) showed that both emulsions presented good stability $(100 \%)$ at room temperature. At $40^{\circ} \mathrm{C}$, both emulsions showed the same stability with the only difference that the $7 / 3$ ratio emulsion has in addition to a lipid layer, an aqueous layer of $1.9 \%$. However, at $4^{\circ} \mathrm{C}$ both emulsions showed a high proportion of an emulsified layer and an aqueous layer of greater instability in the $3 / 7$ ratio emulsion (4.5\%).

Besides, the average size of the globules was 3.51 $\pm 2.32 \mu \mathrm{m}$ (Table 6). The distribution of globules (Figure 5) showed higher concentration (61.33\%) of globules of size $1.25 \mu \mathrm{m}$ in the $4 / 6$ ratio emulsion rather than in the $3 / 7$ ratio emulsion (42.33\%). The cumulative distribution of globules was $72.66 \%$ of globules less than or equal to $3.75 \mu \mathrm{m}$ in the $3 / 7$ ratio emulsion while it was $86.33 \%$ in the $4 / 6$ ratio emulsion. 


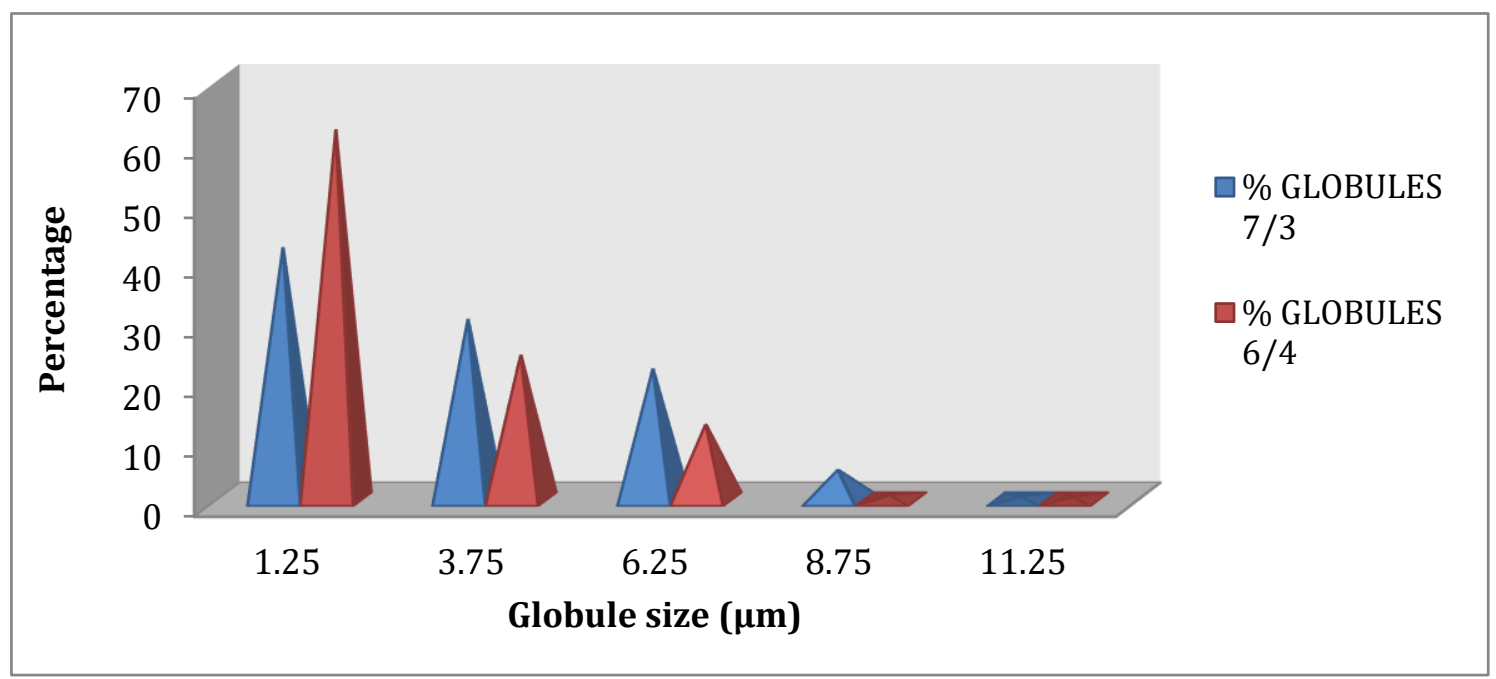

Figure 5 Size distribution of globules in emulsion HLB7 3/7 and HLB7 4/6

The organoleptic aspects of the two emulsions are shown in Table 7 below.

Table 7 Emulsion stability following the quantitative ratio hydrophilic/lipophilic

\begin{tabular}{|c|c|c|l|}
\hline HLB ID & H/L Balance & Fluidity & Aspect \\
\hline 7 & $4 / 6$ & + & Whitish \\
\hline 7 & $3 / 7$ & \pm & Slightly yellowish \\
\hline
\end{tabular}

It appears that the HLB7 4/6 emulsion was fluid with a whitish appearance while the HLB7 3/7 emulsion was more or less fluid with a slightly yellowish appearance.

\subsection{Determination of the emulsion behavior}

After diluting the prepared emulsion in water and Olea europaea oil respectively, the behavior of the mixture was observed one hour later without moving the tube (Figure 6).

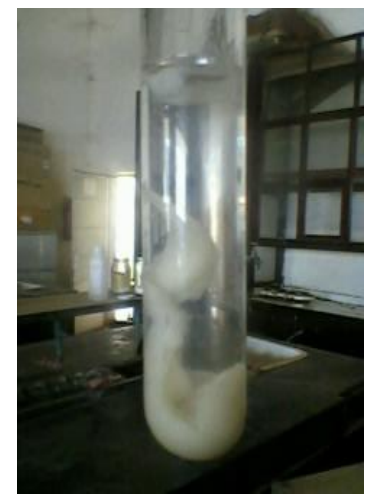

Before

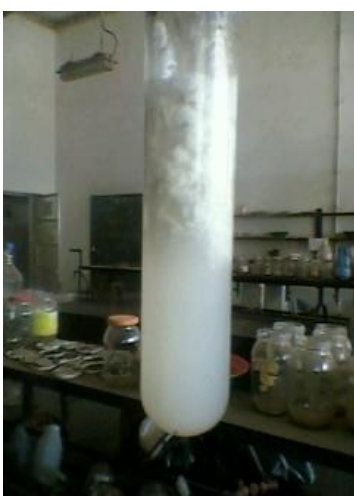

After 1 hour

[A] Emulsion diluted in water

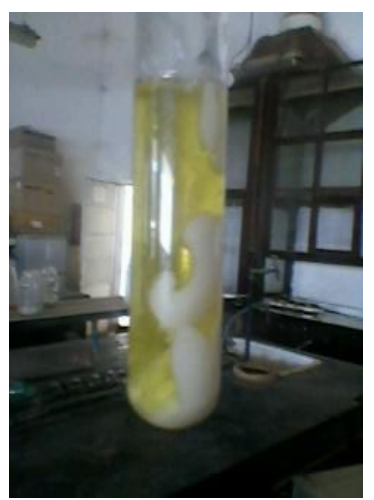

Before

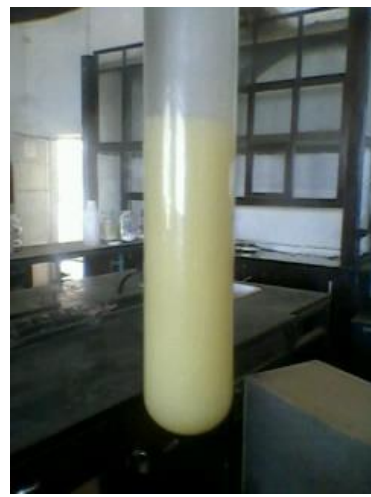

After 1 hour

[B] Emulsion diluted in Olea europaea oil

Figure 6 Emulsion behavior in water and oil

It appears that the emulsion (Figure 6) was well dissolved in oil forming a stable homogeneous oil phase than in water. 


\subsection{Assessment of biological activity}

The evolution of hair growth of Cavia porcellus treated with emulsions and untreated Cavia porcellus was observed for 28 days. The images below illustrate these observations (Figure 7).

After plucking and applying emulsions to the bald area (Figure 7), it was found that on the third day the guinea pigs in groups II, III, and IV showed an appearance of hair in the fluff form. This down was more intense in-group IV than in the other two groups. The group I showed no remarkable change on the third day. Besides, on the $7^{\text {th }}$ day, there was remarkable hair growth in groups II, and III (about 20\% recovery from the original size), and group IV with about $40 \%$ recovery. Group I, on the other hand, only showed the appearance of fluff. On the $14^{\text {th }}$ day, the hair recovery of about $95 \%$ of the original size was observed in group IV and more or less $50 \%$ in groups II, and III. Group I, on the other hand, showed a recovery of about $40 \%$. Finally, on the $28^{\text {th }}$ day, it was found that the guinea pigs of groups I, II, and III were characterized by a total recovery of the coat while this stage was reached by the guinea pigs of group IV on the $21^{\text {st }}$ day.

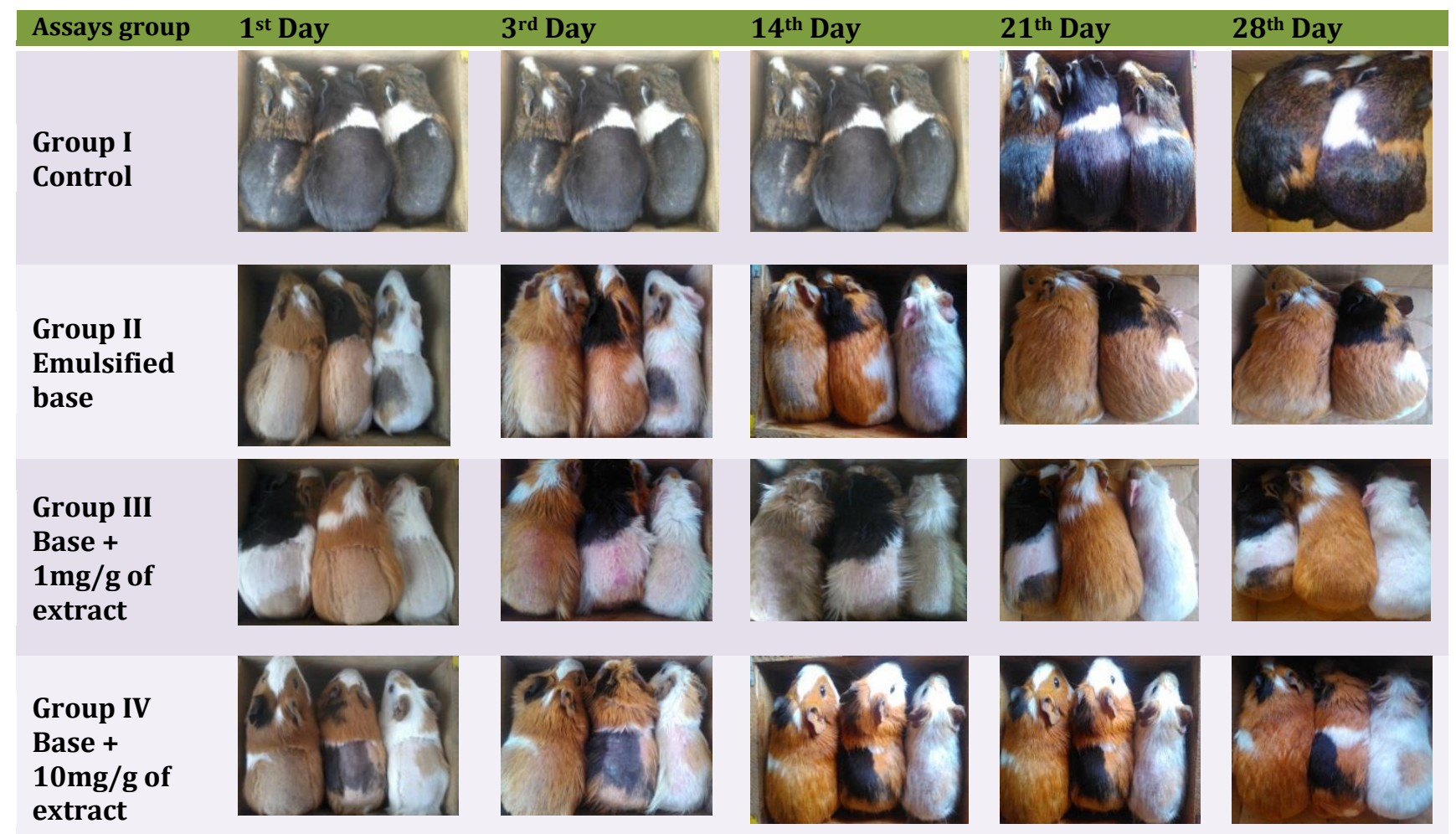

Figure 7 Observation of the fur growth on Cavia porcellus

\section{Discussion}

\subsection{Globules size distribution}

The emulsion HLB 5 was more unstable by the simple fact that its globules have a mean size of $4.57 \pm 3.17 \mu \mathrm{m}$ affected by a great dispersion that is the meaning a lack of uniformity. The study of cumulative frequency showed that only $32.5 \%$ of globules had a greater or equal size than $5 \mu \mathrm{m}$. Since its size distribution is not narrow, this emulsion had not only large average size of the globules but also a poor homogeneity with two modes. Nevertheless, it remained in the range of medium-sized emulsion in the classification because its average diameter was less than $5 \mu \mathrm{m}[14]$.

Furthermore, the emulsion of HLB 6 was more stable than the previous one with a low mean globules size $(2.97 \pm 1.94$ $\mu \mathrm{m})$. The size distribution was wide, whilst remaining concentrated in two classes that represent nearly $85.33 \%$ of globules distributed in the two classes of small size $(1.25$ and $3.75 \mu \mathrm{m})$, which was justified by a low standard deviation compared to that of the emulsion of HLB 5. Globally, this emulsion had a better homogeneity than the previous one with $85.3 \%$ of globules having a diameter less than $3.75 \mu \mathrm{m}$.

Finally, the emulsion of HLB 7 was the most homogeneous of all. It has a very narrow distribution of globules size, and the majority of its globules $(62 \%)$ were in the class of the smaller size $(1.15 \mu \mathrm{m})$. Indeed, the average size of globules was also low $(2.57 \pm 1.91 \mu \mathrm{m})$. There was the high number of the particle of low size, for which the dispersion was very 
low; thus, the emulsion was stable and finely divided. The globules, which had a larger size (greater than $3.75 \mu \mathrm{m}$ ) destabilize the least because they represent only $13.67 \%$ of globules. Therefore, this was demonstrated by the low dispersion showing over the homogeneity of the emulsions [14].

The stability of emulsions evaluated by this method was influenced by the value of the required HLB. Indeed, the stability of the emulsion increases with the HLB. Contrary to the conclusion of Gullapalli and Sheth (1999) [19] who showed that stability concerning the globule's size is not influenced by the value of the required HLB. Furthermore, it was found that if the average globule diameter of the emulsion is small, it is stable. This observation is consistent with Stokes' law [17]. Indeed, the size of the globules, according to this law, influences the rate of creaming and sedimentation. It is therefore a stability parameter, but alone, it is not sufficient to judge the stability of an emulsion. Indeed, the emulsions prepared had an average diameter of less than $5 \mu \mathrm{m}$. This allowed them to be classified as medium emulsions, hence their milky and whitish appearance [14].

\subsection{Determination of stability at different temperatures.}

The absence of instability phenomenon at room temperature could be explained by several reasons. Firstly, the waterin-oil emulsions (W/O) type is supposed to be slimmer to increase the stability compared to Stokes' law. Secondly, several other climatological and environmental elements generally influence the stability of preparations but particularly emulsions. In this case, according to the WHO classification, our study was conducted in Lubumbashi (southern part of DRC), which is in climate zone IV [20,21]. While this may be contrasted, it should be noted that our study was carried out during the dry season (July/August), a period when the ambient temperature is relatively low in Lubumbashi $\left(<22^{\circ} \mathrm{C}\right)[22]$.

Better stability is observed upon storage at $4^{\circ} \mathrm{C}$ in comparison to when it is stored at $40^{\circ} \mathrm{C}$. All the emulsions tested had the average stability of $95.33 \%$ at $4^{\circ} \mathrm{C}$ against $93.97 \%$ at $40^{\circ} \mathrm{C}$. Stokes' law [17] explains the decrease in the stability observed at high temperatures. The rise in temperature decreases the viscosity, which causes an increase in the rate of sedimentation or creaming. Besides, the results of the present study corroborate with the recommended storage conditions for creams: "Keep cool". Because of the above, the stability of emulsions at different temperatures confirms that the emulsion of HLB 7 is more stable than HLB6 and HLB5 emulsions.

\subsection{Hydrophilic-lipophilic ratio}

Two emulsions of HLB 7 were prepared with different hydrophilic/lipophilic ratios (3/7 and 4/6). They presented different stabilities so that the emulsion of the ratio $4 / 6$ was more stable than that of $3 / 7$.

From the point of view of globule size distribution, the $4 / 6$ ratio emulsion was the most stable because it presented a greater homogeneity with $86.33 \%$ of globules having an average size less than or equal to $3.75 \mu \mathrm{m}$ against $72.66 \%$ for the 3/7 ratio emulsion. This phase ratio is in line with the one recommended by the Aromazone cosmetic group, i.e. a hydrophilic/lipophilic ratio of $4 / 6$ for the preparation of W/0 type creams. Moreover, the 3/7 ratio emulsion having an average size of $3.51 \pm 2.32 \mu \mathrm{m}$ compared to the $4 / 6$ ratio emulsion having an average size of $2.57 \pm 1.91 \mu \mathrm{m}$ reflects a lower homogeneity than the latter because the dispersion of the particles was greater. The stability here is therefore not only dependent on the HLB as concluded by Gullapalli and Sheth (1999) [19], but also by the hydrophilic/lipophilic ratio.

The stability at different temperatures confirmed the observation made on the globule size study because although both emulsions showed good stability at room temperature and this for the same reasons mentioned above. The variation of the hydrophilic/lipophilic ratios as a function of temperature showed that the HLB emulsion required with the hydrophilic/lipophilic ratio 3/7 proved to be the least stable. This result is similar to that of Silviya et al. (2010) [23] who concluded from rheological methods that for emulsions of cosmetic products containing natural extracts, the change in elastic module depended on the temperature and composition of the formulations. Thus for the two emulsions that were prepared under the same temperature conditions, it was the composition that influenced the stability [23].

\section{$4.4 \mathrm{pH}$ effect}

The $\mathrm{pH}$ of the emulsions of required HLB prepared with different concentrations of Hibiscus flowers extract and Cannabis oil was done by a direct method. The result indicates that the emulsion without extract and those containing $1 \mathrm{mg} / \mathrm{g}$ of extract had the same $\mathrm{pH}(6.6)$ while the emulsion prepared at $10 \mathrm{mg} / \mathrm{g}$ of extract had a $\mathrm{pH}$ of 6.3 , which shows that a slight acidity increases with the concentration of extract added as observed by Nielloud et al. (2013) [24]. In their study, they showed that in the development of a cosmetic microemulsion, it got a $\mathrm{pH}$ of 5.52 without the active ingredient and a $\mathrm{pH}$ of 5.37 when the active ingredient was used [24]. It should be noted that it is also necessary to take into account the physicochemical properties of the active ingredient, which can undoubtedly influence this factor towards both basicity and acidity. 
The $\mathrm{pH}$ is an important parameter that must be adapted according to the route of administration; it has been adjusted with acetic acid to a value of 5.5, which is a recommended value for dermal preparations because this $\mathrm{pH}$ is close to that of the skin and will therefore be better tolerated $[14,15]$.

\subsection{Biological activity assessment}

This study not only deals with the galenic formulation but also with the existence and conservation of the hair growth stimulating properties of the substances used in the preparation of emulsions.

The results obtained in our work show the beginning of hair growth in the form of down (considered as the beginning of the anagen phase) from the 3rd day, for all the treated groups, with a more pronounced appearance for group IV $(10 \mathrm{mg} / \mathrm{g}$ of extracts). However, the control group did not reach this stage until the seventh day. From this observation, it is believed that the prepared emulsions allowed the growth of the tested Cavia porcellus L hairs. From the third day onwards, the emulsions stimulated hair growth by accelerating the anagen phase.

Our results corroborate those of Park et al (2011) [18] who obtained an appearance of hair on the 7th day with the groups receiving the extract of Fructus panax ginseng while his control group did not experience this stage until the 12th day on rats. The difference in days of onset between our work and Park et al. (2011) would be justified by the fact that in the present study, Cavia porcellus L. was used instead of rats. Moreover, the products administered contained, in addition to the Hibiscus extracts, an emulsified base rich in fatty acids that may contain active and/or nutritive substances [25].

The observation made on the 14th day shows an exceptional difference between group IV (10mg/g of extract) which recovered nearly $95 \%$ of the original hair size and the other groups II and III, which joined each other in presenting the same result and finally group I. This observation confirms that the extracts of hibiscus flower and cannabis seed oil incorporated with the other components of the emulsion have an activity that stimulates and accelerates hair growth [26]. Furthermore, from the results of groups II and III, it arises that at the concentration of $1 \mathrm{mg} / \mathrm{g}$, the tested emulsion did not show any activity different from that of the emulsion without extract; this concentration is, therefore, lower than that which could induce activity. The emulsified base also showed activity with a difference at the beginning of the growth ( $3^{\text {rd }}$ and $7^{\text {th }}$ day) but from the 14 th day the difference was no longer very significant compared to the control group; this suggests that the substances constituting the base of the tested emulsion would stimulate the anagen phase of the hair cycle.

The total recovery is observed on the 21st day for the IV group (10mg/g of extract) and on the 28th day for the other groups. This finding further confirms the observation that the hibiscus flower and cannabis seed oil extracts at $10 \mathrm{mg} / \mathrm{g}$ incorporated in the composition of the emulsion studied have an activity that stimulates and accelerates hair growth.

\section{Conclusion}

The stability of a water-in-oil emulsion formulated with natural substances selected for our work depends on the hydrophilic-lipophilic balance, the homogeneity of the distribution of the globules, their average size, as well as the hydrophilic/lipophilic ratio.

The water-in-oil type emulsions with a ratio of 4/6 and an HLB of 7 comprising Cannabis sativa L. seed oil (10mg/g), Ricinus communis L. seed oil, olive oil (Olea europaea), hydromethanolic extract of Hibiscus rosa-sinensis L. (10mg/g), and yellow beeswax showed hair growth stimulating activity.

The results obtained during this work open other research horizons in the same theme, in particular toxicological tests, the improvement of the formulation, the tests with other concentrations, the study of follow-up of histological sections of the influence of this emulsion on the nature of the hair.

\section{Compliance with ethical standards}

\section{Acknowledgments}

The authors would like to acknowledge the Departments of Pharmacy and Chemistry, the University of Lubumbashi in DR Congo for providing the necessary equipment to achieve this study.

\section{Disclosure of conflict of interest}

The authors declare no competing interests. 


\section{Statement of ethical approval}

All experiments were conducted under the ethical standards of the institutional and/or national research committee and with the Helsinki declaration as well as its later amendments or comparable ethical standards principles for the treatment of laboratory animals in accordance.

\section{References}

[1] Bruinsma W. Alopécies, chutes de cheveux. In Guide des éruptions médicamenteuses. Ed. Arnette, Paris. 1989; 9-11

[2] Bonvalet D. Les alopécies cicatricielles, in Pathologie du cheveu et du cuir chevelu ; Ed. Masson, Paris. 1999 ; $172-$ 184.

[3] Pamplona-Roger GD. Santé par les plantes médicinales ; Edition Safeliz ; Espagne. 2009 ; 176, 262, 330, 345,365

[4] Satish P, Vikas S, Nagendra SC, Mayank T, Dixit VK. Hair Growth: Focus on Herbal Therapeutic Agent. Current Drug Discovery Technologies. 2015 ; 12: 00-001

[5] Kubo M, Matsuda H, Fukui, Nakai MY. Development studies of cuticle drugs from natural resources. I. Effects of crude drug extracts on hair growth in mice. Yakugaku Zasshi. 1988; 108: 971-978.

[6] Ross IA. Medicinal Plants of the World: Chemical Constituents, Traditional and Modern Medicinal; Vol. 3, Humana Press, New Jersey. 2005; 469

[7] Fleurenti J, Hayon JC. Les plantes qui nous soignent : Traditions et thérapeutique ; Edition OUEST-France. 2007; $12-13$

[8] Rele AS, Mohile RB. Effect of mineral oil, sunflower oil and coconut oil on prevention of hair damage. J Cosmet Sci. 2003; 54(2): 175-192

[9] Scarpa A, Guerci A. Various uses of the castor oil plant (Ricinus communis L.). A review. Journal of Ethnopharmacology. $1982 ; 5: 117-137$

[10] Grotenhermen F. Cannabis en médecine ; éd. TEC et DOC, Paris. 2001 ; 22

[11] Paris M, Hurabielle M. Abrégé de matière médicale (Pharmacognosie) ; Tome 1, Généralités monographiques. Edition Masson. 1981; 13-15, 169, 171-173, 177-178

[12] Nil L, Labonté R. Préparation de la cire d'abeille; Bulletin du gouvernement du Québec ; Ministère de l'agriculture des pêches et de l'alimentation/Apiculture. 1981..

[13] Leclercq B. Abeille qui es-tu ? CD-ROM. 2011.

[14] Le Hir A. Pharmacie galénique : Bonne pratique de fabrication des médicaments ; 8ème édition ; Masson ; Paris. $2001 ; 62,85,90-92,158-166,384-385$.

[15] Charpentier B et al. Guide du préparateur en pharmacie ; 3ème édition ; Masson. 2008 ; 777, 794, 1096.

[16] Py C, Rouviere J. Investigation fondamentale des Emulsions Multiples H/L/H pour application cosmétique: Formulation-Etude de stabilité, Université de Montpellier 2 ; Thèse. 1995.

[17] Wehrlé P. Pharmacie galénique : formulation et technologie pharmaceutique ; Edition. Maloine ; Paris. 2007 ; 162-171.

[18] Park S, Shin W, Ho J. Fructus panax ginseng extract promotes hair regeneration in C57BL/6 mice; Ethnopharmacology. 2011; 138: 340-344.

[19] Gullapalli RP, Sheth BB. Influence of an optimized non-ionic emulsifier blend on properties of oil-in-water emulsions; Eur.J.Pharm.Biopharm. 1999; 48(3):233-238.

[20] Haynes JD. Worldwide virtual temperatures for product stability testing. Journal of pharmaceutical sciences. 1971; 60: 927-929.

[21] Dietz R, Feilner K et al. Drug stability testing-classification of countries according to climatic zone. Drug Made Ger. 1993; 36: 99-103.

[22] Pain M, Bruneau JC. Atlas de Lubumbashi. Ed. Centre d'études géographique sur l'Afrique noire, université de Paris X- Naterne. $1990 ; 132-133$.

[23] Silviya G, Maria K, Silvia A. Etude des émulsions cosmétiques aux extraits naturels par des méthodes rhéologiques (Effet de la température). Revue de génie industriel. 2010 ; $5: 133-142$. 
[24] Nielloud F, Mestres JP, Fortune R, Draussin S, Marti-Mestres G. Formulation of oil-in-water submicron emulsions in the dermatological field using experimental design. Polym. Int. 2003. 52:610-613. doi: 10.1002/pi.1100

[25] Bruneton J. Pharmacognosie, Phytochimie, Plantes médicinales. 3ème édition ; TEC et DOC. Paris. 2009.; 147, 155-156.

[26] Huang MF, Hang WJ, Zhong Q. Hair growth stimulating preparations containing medicinal plant extracts; Patentfaming Zhuanli Shenquing Gongkai Shuomingshu-1,. 1990; 43: 624-626. 